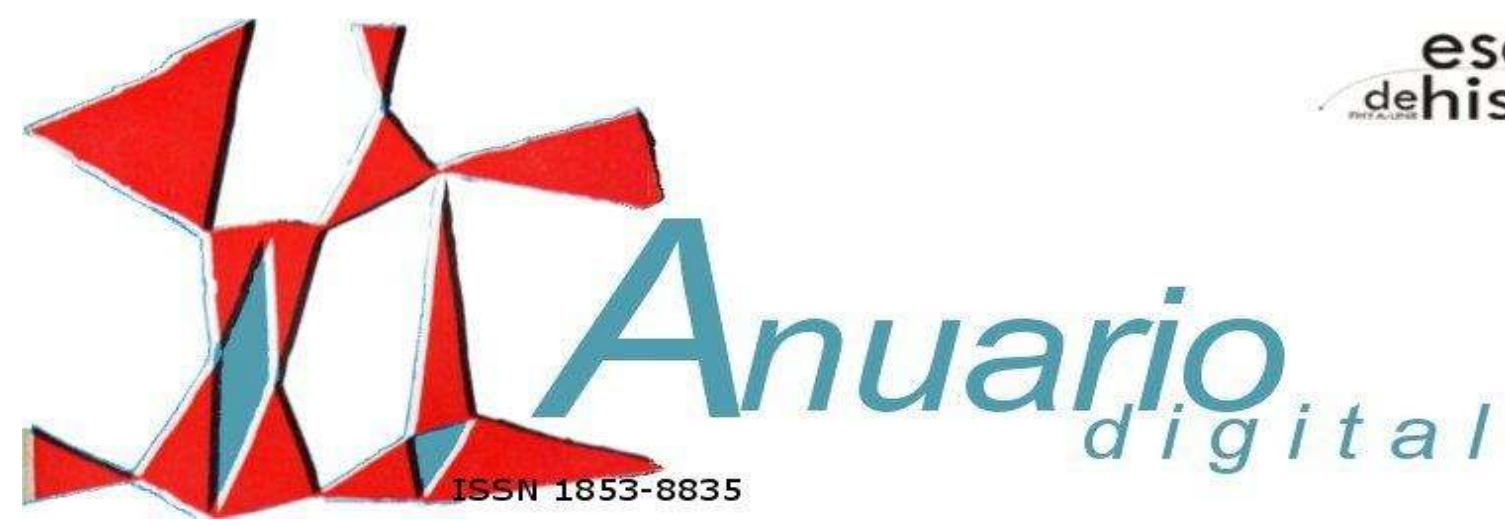

\title{
LA OFICINA DE URBANISMO: TRANSFORMACIONES INSTITUCIONALES DE BOGOTÁ Y BUENOS AIRES, UNA PERSPECTIVA COMPARATIVA ENTRE 1946-1953
}

\section{RESUMEN}

El objetivo de este artículo es comparar las transformaciones institucionales acontecidas en los gobiernos de Bogotá y Buenos Aires que sirvieron de bases para desarrollar el urbanismo moderno de los Congresos Internacionales de Arquitectura Moderna, CIAM. Se busca analizar un periodo en el cual tanto en Argentina como en Colombia ocurrieron acontecimientos políticos fundamentales -el surgimiento del peronismo en el primer caso y el inicio del período conocido como la Violencia en el segundo- en relación con el establecimiento de una nueva forma de pensar la ciudad. El corpus documental de este artículo está compuesto principalmente por documentación oficial como Acuerdos, Decretos y Leyes. Lo cual permite entender de primera mano cómo se reorganizaron los aparatos gubernamentales para dar cabida a esta nueva doctrina. Esta historia busca comprender cómo se articulan los espacios institucionales en ciudades capitales con los desarrollos profesionales de un urbanismo internacional.

Palabras clave: Bogotá - Buenos Aires - historia institucional - urbanismo

\footnotetext{
*EHESS, Centre de Recherches historiques, Especialidad, Territoires, Sociétés et Développement.
} 
THE BUREAU OF URBANISM: INSTITUTIONAL TRANSFORMATIONS IN BOGOTÁ AND BUENOS AIRES, A COMPARATIVE PERSPECTIVE, 1946-1953.

The purpose of this article is to compare the institutional transformations underwent by the governments of Bogotá and Buenos Aires upon which the projects of modern urbanism of the International Congresses of Modern Architecture CIAM- were developed. It analyzes a period in which, both in Argentina and Colombia, major political changes happened -the arrival of peronism and the beginning of Violence respectively-modifying the way of conceiving the city. The sources of the article are mainly official documents like, laws, decrees and accords. This history seeks to understand how different institutional spaces in capital cities interacted in a similar manner with an international urbanism.

Key words: Bogotá - Buenos Aires - institutional history - urbanism

\section{Introducción}

A mediados de siglo XX tanto Bogotá como Buenos Aires habían construido estructuras institucionales sobre las cuales se desarrollaban proyectos de urbanismo fundamentales para la ciudad. Sin embargo, en la década de 1940, acontecimientos de importancia nacional introdujeron cambios en la manera de gobernar estos dos países y en las condiciones sociales y políticas nacionales, que, a su vez, modificaron la manera de pensar y gobernar las ciudades capitales. El cambio principal consistió en que los gobiernos nacionales, que habían jugado hasta entonces un papel secundario en el proceso de construcción del sistema institucional del urbanismo, tomaron las riendas de este proceso y plasmaron sus intereses directamente en las oficinas municipales. En este momento, se introdujo tanto en Bogotá como en Buenos Aires el urbanismo moderno de los Congresos Internacionales de Arquitectura Moderna (CIAM) en el sistema institucional y de gobierno. En este artículo se analizan estos dos procesos con base en una metodología comparativa.

A principios de los años 1940 tuvo lugar en Argentina la denominada Revolución del 43. El presidente Ramón Castillo fue derrocado y el General Pedro Pablo Ramírez asumió la presidencia de la Nación. Asimismo, Basilio Pertiné fue nombrado Intendente de Buenos Aires. Este acontecimiento puede considerarse como un relevo general en la política nacional argentina, gracias al cual se abrió un espacio para la participación de un nuevo grupo político liderado por Juan Domingo Perón, quien ocuparía la presidencia desde 1946. Más allá del relevo de individuos, la transformación vivida en estos años puede ser

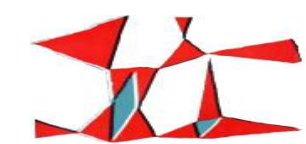

Anuario № 25, Escuela de Historia 
entendida como un viraje en la manera de hacer política y de concebir las instituciones estatales y municipales. El acceso al poder de este grupo fue interpretado por sus protagonistas como el inicio de la construcción de una nueva Argentina en la cual el progreso urbano era un elemento esencial. En este proceso de re-fundación de la nación se le asignó a la ciudad capital un papel central. De esta manera, se buscó cambiar el rol del urbanismo de Buenos Aires, y para ello se creó en el ejecutivo municipal una sección llamada Estudio para el Plan de Buenos Aires (EPBA), cuyas ideas provenían del urbanismo moderno de los CIAM.

Por otra parte, en Colombia, en 1946 el partido Conservador regresó al poder luego de 16 años de gobiernos consecutivos del partido Liberal. La transición ocurrió en medio de una fuerte polarización política que rápidamente se tornaba violenta. El nuevo gobierno buscó modificar aspectos claves de la estructura institucional para tomar control del desarrollo urbano. Y, al mismo tiempo, abrió un espacio para que se desarrollara un urbanismo basado en el modernismo de los CIAM. Posteriormente, el 9 de abril de 1948, ocurrió otro acontecimiento de gran importancia para la capital. Jorge Eliécer Gaitán, un líder político del partido Liberal, ex-candidato presidencial, ex-alcalde de la ciudad fue asesinado en plena calle y la población bogotana reaccionó masivamente. La violencia explotó en la capital. Institucionalizar una nueva manera de pensar y construir la ciudad era entonces una tarea extremadamente difícil, pero, al mismo tiempo, imperativa para los intereses del gobierno. Desde entonces, se vivió en Colombia un periodo violento y políticamente incierto. Pero, a pesar de la inestabilidad política, se estableció en el ejecutivo municipal una Oficina del Plano Regulador de Bogotá (OPRB) que operó con base en las ideas de Le Corbusier, Jose Luis Sert y Paul Lester Wiener.

El interés de esta comparación no es el de yuxtaponer dos configuraciones socio-políticas distintas sólo porque ocurrieron simultáneamente. Se trata, por el contrario, de entender una dinámica política e institucional de manera transversal y de esta forma comprender los vínculos entre urbanismo, política y estructuras institucionales. Además, la comparación permite entender cómo en configuraciones sociopolíticas distintas se desarrollan procesos institucionales y de urbanismo similares. Lo cual permitirá plantear reflexiones sobre la manera en que los grupos en el poder entendieron el rol del urbanismo y su relación con las estructuras institucionales a mediados del siglo XX en las ciudades capitales. ¿Cómo se adaptaron las ideas de urbanismo a las estructuras institucionales municipales? ¿Cuál era la labor de los

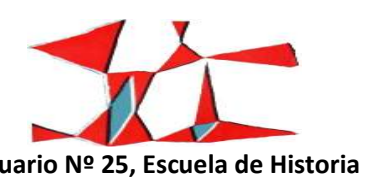


expertos en urbanismo? Y ¿cómo y con qué criterios e intereses se definieron sus responsabilidades? De este modo, se entenderá también cuáles fueron las bases sobre las que se reestructuró la ciudad a mediados del siglo pasado.

Varias ciudades de América Latina vivieron procesos similares y otras comparaciones aportarían elementos interesantes a la reflexión sobre las formas en las cuales se construyeron y reestructuraron sistemas institucionales para el urbanismo. Lo particular de estas dos capitales es que vivieron simultáneamente un cambio ideológico en la política en sentidos opuestos, y un cambio a favor del urbanismo moderno de los CIAM. Estas situaciones, en ambos casos, generaron transformaciones institucionales que más que un trasfondo de la historia política aportan elementos esenciales para entender cómo se pensaron las ciudades capitales a mediados de siglo en ambos países.

\section{Bogotá: conservadores, violencia y modernismo}

Por más de veinte años las instituciones municipales, especialmente la Secretaría de Obras Públicas de Bogotá (SOP) creada en 1926, desarrollaron un sistema oficial de control de la urbanización y la construcción en la ciudad. Hasta finales de los años 1930 este sistema supo articular la acción institucional con la inversión de capitales logrando resultados satisfactorios y constituyendo una estructura de acción compleja. Igualmente, las autoridades municipales establecieron un sistema en el cual dos instituciones, la Secretaría de Obras Públicas y el Departamento de Urbanismo dirigían la urbanización de la ciudad. En este sistema la representación del gobierno nacional era importante pero indirecta. Es decir, el gobierno nacional daba la base legal para la existencia de los organismos ejecutivos municipales, como la SOP, pero eran ellos mismos quienes definían tanto los objetivos y principios como los mecanismos prácticos y las herramientas técnicas para el desarrollo de los proyectos de urbanismo. Sin embargo, a finales de los años 1940 una nueva ley obligó a las ciudades a crear planos directores y generó, de esta manera, un cambio fundamental en la estructura del urbanismo de la capital y de otras ciudades del país.

Desde el inicio de su administración en 1946 el nuevo gobierno consideró necesario que las ciudades y áreas urbanas del país crearan planes reguladores para definir su desarrollo futuro. Esta decisión fue oficializada por la ley № 88 de 1947, que se basó en una interpretación del urbanismo que consideraba que una ciudad no podía ser gobernada sin un plan regulador. En ese sentido, un sistema como el bogotano 116

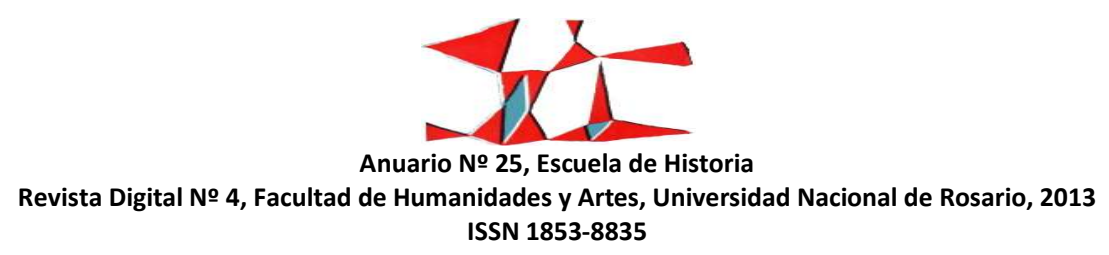


que hasta entonces no se basaba en ese tipo de herramientas técnicas, se vio en la necesidad y obligación legal de cambiar su manera de entender el urbanismo.

La idea de establecer un plan regulador en Bogotá en 1947 suponía importantes transformaciones institucionales. A diferencia de la experiencia vivida por proyectos como "Bogotá Futuro" en los años 1920, en los años 1940 existía ya una estructura institucional compleja que contaba con los siguientes tres elementos. En primer lugar, la SOP y en ella el Departamento de Urbanismo era una sección importante del gobierno municipal que funcionaba de manera relativamente autónoma; segundo, se habían consolidado modos de acción institucional con base en un lenguaje técnico, y en una manera de pensar el urbanismo ${ }^{1}$; y finalmente, el gobierno municipal, en la SOP, contaba con personal técnico y administrativo que tenía responsabilidades claras, competencias cada vez más profesionales y manejaba recursos municipales. Así, la iniciativa del gobierno nacional, más que proponer cambios en las herramientas técnicas de urbanismo, proponía una transformación radical en la manera de pensar el país, sus ciudades y en especial, la ciudad capital.

La ley № 88 de 1947 fue la propuesta del gobierno nacional para reformar el sistema urbano, detengámonos por el momento en este texto para analizar cuidadosamente los nuevos términos propuestos. Los tres primeros artículos definían el concepto de "superficie urbana" sobre el cual se basó la ley. Los artículos $2^{\circ}$ y 3 o son particularmente interesantes, pues, redefinían las responsabilidades municipales en el proceso de construcción de los espacios urbanos. El artículo 2, para empezar, estableció que "Los Concejos de cada Distrito estimularán las construcciones urbanas, a fin de evitar la solución de continuidad de las edificaciones, que tanto perjudican la buena presentación de las localidades.”² En ese sentido, se trataba de una disposición que establecía las directrices de estética urbana que debían seguir las municipalidades. Igualmente, se puede ver que el mensaje de fondo era que la construcción de la ciudad, si bien materialmente seguía en manos de las municipalidades, debía hacerse con base en los criterios establecidos por el Estado nacional. Enseguida, el artículo 3 determinó que "Los Concejos Municipales dictarán las providencias necesarias para que las nuevas construcciones urbanas no perjudiquen la

\footnotetext{
${ }^{1}$ Basada en las enseñanzas del urbanista austriaco Karl H. Brunner, director del Departamento de Urbanismo desde 1933 y profesor de la cátedra de urbanismo de la carrera de Arquitectura de la Universidad Nacional.

${ }^{2}$ Municipio de Bogotá, “Ley №88 de 1947”; Registro Municipal de Bogotá; Imprenta Municipal; Bogotá; 15 de septiembre de 1948; Año LXVII; № 307 a 377; pp. 351-352. "Artículo $2^{\circ}$ Los Concejos de cada Distrito estimularán las construcciones urbanas, a fin de evitar la solución de continuidad de las edificaciones, que tanto perjudican la buena presentación de las localidades."
}

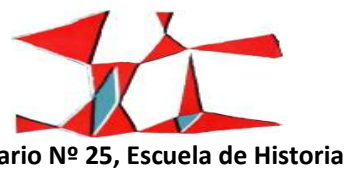


alineación de las calles ni el plano de urbanización general. ${ }^{3}$ Con esta medida, el gobierno nacional aclaró lo dictaminado en el artículo anterior, pues además de establecer los objetivos de fondo fijó un mecanismo práctico que debían desarrollar e implementar los ejecutivos locales. De esta forma, la creación y uso de un "plano de urbanización general", pasó a ser una obligación legal de los municipios. Más aún, la "buena presentación de las localidades" según los términos de la ley, dependía del uso del "plano de urbanización general".

Fijar los principios legales de fondo sobre los cuales se debía basar la urbanización en el país era una manera de controlar el desarrollo de las ciudades. Pero, también era el resultado de una nueva manera de entender el territorio nacional. La idea fundamental sobre la cual se basaba la nueva ley consistía en que, para el nuevo gobierno, el país estaba compuesto por una configuración de espacios en los cuales las zonas urbanas debían ser reguladas por criterios unívocos del Estado nacional. Si bien el país no era aún primordialmente urbano, este tipo de medidas muestran la manera en que el Estado empezó a lidiar con una creciente tendencia a la urbanización ${ }^{4}$. A la luz de esto, es claro que además de establecer objetivos y principios generales, el Estado buscaba controlar hasta las herramientas técnicas y mecanismos ejecutivos para pensar y desarrollar las ciudades.

Esta ley cobijaba todos los municipios del país, sin embargo, el Estado reconocía diferencias entre ellos y estableció procesos distintos para su control. La diferenciación de estos espacios se hizo, según el artículo 7 de la ley № 88, con base en criterios monetarios.

“Los Municipios que tengan un presupuesto no inferior a doscientos mil pesos (\$200.000) están en la obligación de levantar el plano regulador que indique la manera como debe continuarse la urbanización futura de la ciudad. Este plano no sólo comprenderá las enmiendas y mejoras deban hacerse a la parte ya construida, atendiendo al posible desarrollo, sino los nuevos barrios que hayan de levantarse, así como los sitios donde deban ubicarse los edificios públicos, sitios de recreo y deporte, templos, plazas y áreas verdes, escuelas y demás edificios necesarios a la población." ${ }^{5}$

\footnotetext{
${ }^{3}$ Ibídem.

${ }^{4}$ Gouëset, Vincent; Bogotá: Nacimiento de una metrópoli. La originalidad del proceso de concentración urbana en Colombia en el siglo XX; Tercer Mundo Editores; Bogotá; 1998.

${ }^{5}$ Municipio de Bogotá; "Ley №88 de 1947"; Ob. Cit.; pp. 351-352.
}

118

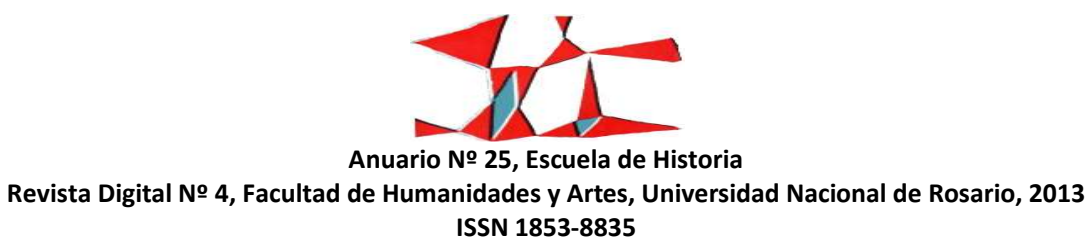


El criterio presupuestal como base para obligar a las ciudades a levantar un plano regulador, más que una manera de jerarquizar el sistema urbano expresaba la idea de que eventualmente todos los municipios deberían utilizar esta herramienta. Sin embargo, obligar a un municipio sin recursos a realizar un proyecto de urbanismo moderno, requeriría una inyección presupuestal de parte del Estado nacional, ya que, de no hacerlo, muchos municipios quedarían por fuera de la legalidad. Así, por lo pronto, sólo se hizo obligatorio para las ciudades que ya contaran con los recursos para desarrollarlo. No se trataba entonces de una manera de diferenciar unos municipios de otros, por el contrario, fue una estrategia de acción que permitía avanzar de manera progresiva sin necesidad de comprometer recursos del Estado.

Bogotá sobrepasaba ampliamente la suma requerida y por lo tanto estaba en la obligación de levantar un plano regulador. Para esto necesitaba buscar un experto, bien fuera local o extranjero, que pudiese crear y poner en marcha el plano director ${ }^{6}$. Sin embargo, el desarrollo de la vida institucional era menos idílico que como lo presentaba el gobierno nacional. La polarización política entre los partidos conservador y liberal era fuerte y violenta. La historiografía colombiana ha estudiado ampliamente este periodo de la historia nacional ${ }^{7}$ conocido como La Violencia, por lo tanto este artículo no profundiza en este tema. Este periodo se puede delimitar entre 1946 y 1958. Años durante los que diferentes grupos en nombre de las ideologías de los partidos, Conservador y Liberal, se alzaron en armas y se lanzaron a una guerra sangrienta. Los actos de violencia tuvieron lugar en diferentes áreas urbanas y rurales del país.

El nuevo modelo de gobierno del partido Conservador, que había regresado al poder en 1946 luego de 16 años de gobiernos del partido Liberal, contaba con oposiciones fuertes y violentas. Fue así como el 9 de abril de 1948 se escucharon tiros en la esquina de la avenida Jiménez y la carrera séptima y cayó muerto Jorge Eliécer Gaitán, líder político del partido Liberal. La cólera del pueblo se adueñó de las calles y los habitantes de Bogotá salieron enfurecidos a manifestar su malestar. La violencia estalló a tal punto que hubo establecimientos comerciales saqueados, tranvías incendiados y edificios destruidos. Este día se conoce en la historiografía colombiana como El Bogotazo.

\footnotetext{
${ }^{6}$ Podría pensarse que la visita realizada por Le Corbusier en julio del mismo año situaba al urbanista francés en una posición de privilegio. Pues tenía los contactos necesarios, había desarrollado una breve reflexión sobre Bogotá y su trabajo previo era reconocido ampliamente. Sin embargo, a pesar de ser el más célebre de los candidatos no era el único interesado en obtener el contrato con Bogotá. Del mismo modo, tampoco era el único que había puesto en marcha una estrategia para obtener dicho contrato. Otros de los principales aspirantes al contrato eran la compañía creada por José Luis Sert y Paul Lester Wiener Town Planning Associates y un grupo de arquitectos colombianos de la Sociedad Colombiana de Arquitectos y asociados a la revista Proa y liderados por Carlos Martínez.

${ }^{7}$ Ver: Palacios, Marco; Entre la legitimidad y la violencia. Colombia 1875-1994; Norma; Bogotá; 1995.
}

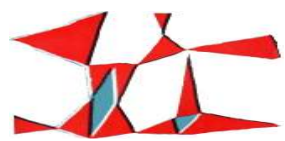

Anuario № 25, Escuela de Historia 
La capacidad destructiva de la masa, como se puede ver en los mapas (Mapas 1 y 2), fue devastadora. Edificios enteros fueron eliminados del mapa y el centro de la ciudad quedó fuertemente deteriorado. Estos daños materiales y el conflicto político violento que se desencadenó en este día requerían análisis, acciones y cambios en todos los niveles de gobierno. La primera interpretación de los hechos la hizo el presidente de la República una semana después del Bogotazo.

El 16 de abril el presidente Ospina expidió el Decreto 1260 de 1948 para la reconstrucción de Bogotá ${ }^{8}$, este texto se basó en el decreto 1239 de 1948 en el cual se determinó que el orden público de Bogotá había sido perturbado y “...que el Gobierno necesita emprender sin demora el planeamiento de los trabajos que se refieran para la reconstrucción de la ciudad de Bogotá." ${ }^{9}$ Con base en este decreto, el gobierno decidió establecer una Junta de Planeamiento,

“Créase la Junta de Planeamiento de la reconstrucción de la ciudad de Bogotá, la cual estará integrada así: el Ministro de Obras Públicas o un representante suyo; el Alcalde de Bogotá; el Secretario de Obras Públicas Departamentales de Cundinamarca; el Secretario de Obras Públicas Municipales de Bogotá; el Director del Departamento de Edificios Nacionales; el Presidente de la Sociedad Colombiana de Arquitectos y el Presidente de la Sociedad Colombiana de Ingenieros; y dos Arquitectos, nombrados por el Presidente de la República." ${ }^{10}$

La tarea asignada a los miembros de este grupo no era la de realizar ellos mismos el plan regulador ordenado por la ley № 88 de 1947. Este decreto era una medida de urgencia para enfrentar una crisis local. La acción inmediata del gobierno nacional pretendía liderar directamente el proceso de pensar y construir la ciudad, lo cual, era una diferencia fundamental con respecto a la manera como operaban los organismos ejecutivos anteriormente. Durante los años 30 y hasta mediados de los 40, era la Secretaría de Obras Públicas de Bogotá el organismo que tomaba las decisiones sobre las obras y proyectos que la ciudad necesitaba y también era el órgano ejecutor. En el nuevo esquema era el gobierno nacional quien decidía cuáles eran las obras y proyectos que la capital necesitaba e igualmente decidía cómo, con base en qué criterios y con qué recursos se debían desarrollar.

\footnotetext{
8 “Decreto 1260 de 1948."; Registro Municipal; Imprenta Municipal; Bogotá; 15 septiembre de 1948; Año LXVIII; № 307-377; pp. 353-354.

${ }^{9}$ Ibídem.

${ }^{10}$ Ibídem.
}

120

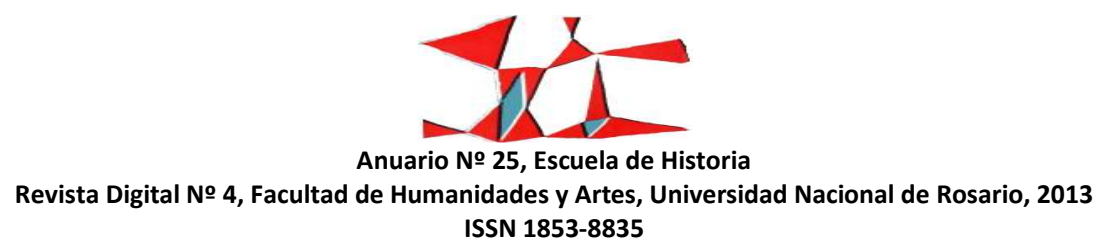


Del mismo modo, la manera de entrar en acción permite entender las fuerzas que se organizaron a través del gobierno para participar en la construcción de Bogotá. En primer lugar, en la lista establecida por el presidente se confirió un puesto de preponderante al Ministro de Obras Públicas, quien nunca antes había participado de este tipo de procesos pero que desde entonces pasó a ser un líder del urbanismo local. En segundo lugar, la presencia de los presidentes de dos sociedades profesionales, la Sociedad Colombiana de Arquitectos (SCA) y la Sociedad Colombiana de Ingenieros (SCI), marcó un cambio en la manera de pensar la ciudad. Pues, ambas sociedades, aunque más enérgicamente la de arquitectos, habían manifestado su desacuerdo con el sistema desarrollado desde 1933. Y la SCA había inclusive propuesto un plan para Bogotá $^{11}$. Por último, el nombramiento de dos arquitectos por parte del Presidente de la República demuestra un interés gubernamental por entender y controlar los proyectos propuestos hasta en sus detalles más técnicos.

La presidencia interpretó los acontecimientos del 9 de abril como la expresión violenta de una crisis nacional y no como un acontecimiento local. Esta lectura no es sorprendente ya que, efectivamente, Jorge Eliécer Gaitán era un personaje de importancia nacional, fue candidato a la Presidencia por el partido Liberal en las elecciones de 1946 y obtuvo la tercera votación (358,957 votos) después del conservador Mariano Ospina Pérez (565,939 votos) y el liberal Gabriel Turbay (441,199 votos). Del mismo modo, la violencia partidista era un fenómeno que había afectado al país entero y un acontecimiento de este tipo, que ocurría en pleno centro de la capital, no podía ser tomado a la ligera.

Por otra parte, según el gobierno el trauma urbano generado por la violencia de aquel día justificaba, por su magnitud, la participación de las instancias más altas y poderosas del gobierno así como la utilización de las mejores herramientas técnicas. El artículo 2 del decreto 1260 determinó que:

"La expresada Junta tendrá a su cargo la ejecución de los estudios técnicos básicos y planificación general de todas las obras de reconstrucción de Bogotá, tanto oficiales como particulares en las áreas afectadas, ya se trate de obras financiadas con fondos nacionales, departamentales o municipales

\footnotetext{
${ }^{11}$ Amorocho, Luz; García, Enrique; Angulo, José y Martínez, Carlos; “Bogotá puede ser una ciudad moderna”; en Proa; № 2; Bogotá; 1946 y Proa; № 3; Bogotá; 1946; pp.14-26.
}

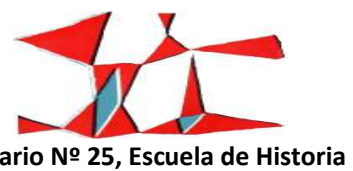

Revista Digital № 4, Facultad de Humanidades y Artes, Universidad Nacional de Rosario, 2013 ISSN 1853-8835 
provenientes de presupuestos ordinarios, empréstitos nacionales y extranjeros, o fondos privados". ${ }^{12}$

En ese sentido, la reconstrucción de Bogotá, tal como la entendió el gobierno nacional fue mucho más que un remplazo de nombres en una cartera municipal. Se trataba, por el contrario, de una verdadera toma de control por parte del ejecutivo nacional de los mecanismos ejecutivos de urbanismo de la capital. Pues, mediante este decreto el gobierno se procuraba los recursos humanos con sus conceptos técnicos pero también los recursos económicos. Además, como lo define el artículo № 3, “El Gobierno estará facultado para abrir créditos o efectuar traslados en el Presupuesto vigente, con el fin de atender a los gastos que demande el funcionamiento de la junta creada por el presente Decreto." ${ }^{13}$ Lo cual, desde el punto de vista económico, generaba un marco de acción amplio controlado por el gobierno nacional. Si bien este decreto se gestó como la respuesta para una zona específica de la ciudad, su alcance, como veremos, pretendía ir mucho más allá del centro. Pues, fue con base en esta manera de pensar que se desarrolló en las instituciones locales y nacionales una nueva manera de pensar la ciudad y el urbanismo.

Más tarde en el año, el Concejo de Bogotá creó, mediante el acuerdo 88 de 1948, un nuevo órgano encargado del urbanismo llamado Oficina del Plano Regulador de Bogotá (OPRB). Esta oficina, como lo determinaba el artículo 1, debía ser organizada por el alcalde ${ }^{14}$. De esta manera, el urbanismo de la capital no requería de la aprobación del gobernador departamental ni de las instancias legislativas municipales, lo cual permitió al gobierno nacional ejercer un mayor control sobre el urbanismo. El alcalde, era un funcionario del gobierno municipal elegido por el presidente.

El artículo 4 del acuerdo 88 determinó las responsabilidades de la OPRB en una lista de 24 actividades. Esta lista muestra los elementos que el gobierno nacional consideraba necesarios para desarrollar un plan regulador. Antes de analizar las ideas propuestas en ella, veamos dos otros artículos del acuerdo que modificaron la configuración institucional con base en la cual se buscaba organizar la oficina de urbanismo. En el artículo 5 se determinó que "La suma necesaria para el desarrollo de este Acuerdo se considerará incluida dentro del Presupuesto Extraordinario de Progreso Urbano, y el Alcalde queda

\footnotetext{
${ }^{12}$ Ob. Cit.; “Decreto 1260 de 1948."; pp. 353-354.

${ }^{13}$ Ibídem.

${ }^{14}$ Concejo de Bogotá; “Acuerdo número 88 De 1948”; en Registro Municipal; Imprenta Municipal; Bogotá; septiembre 15 de 1948 ; Año LXVIII; № 307 a 377; pp. 241-243. "Artículo $1^{\circ}$ El Alcalde procederá a organizar el Departamento encargado de elaborar el plano regulador de la ciudad, Departamento que se denominará "Oficina del Plano Regulador de Bogotá".
}

122

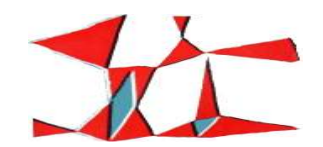

Anuario № 25, Escuela de Historia

Revista Digital № 4, Facultad de Humanidades y Artes, Universidad Nacional de Rosario, 2013 ISSN 1853-8835 
autorizado para hacer los traslados que estime necesarios, con el fin de darle cumplimiento." ${ }^{15}$ Este cambio fue fundamental en la medida en que modificó el procedimiento para obtener los recursos económicos para financiar eventuales proyectos. De esta manera, se le otorgó al alcalde no sólo la responsabilidad política de dirigir el urbanismo, sino también los medios económicos para hacerlo.

Por otra parte, el artículo 6 estableció que “Mientras se elabora el plano regulador de la ciudad, el Alcalde reglamentará por medio del Decreto la altura que deberán tener las nuevas edificaciones en la ciudad. Los Decretos deberán llevar la aprobación del la Comisión de Obras Públicas del Concejo, previo concepto favorable de la Sociedad Colombiana de Arquitectos." ${ }^{16}$ Este trabajo técnico, que anteriormente realizaban los expertos del Departamento de Urbanismo, quedaba entonces en manos de la Alcaldía y sobre todo, de la Sociedad Colombiana de Arquitectos. El decreto sirvió entonces para cambiar la manera de pensar el urbanismo, puesto que incluía a la SCA como garante técnico. Esta sociedad profesional ya había manifestado a través de distintos medios su manera de concebir la ciudad así como su interpretación del rol del urbanista y del Plan Regulador. Al tenerlos en cuenta en la nueva política de urbanismo, y con un rol definido en la estructura institucional, el gobierno validaba su pericia profesional y al mismo tiempo elegía una manera nueva de entender los objetivos del urbanismo. Esta manera, gracias a Carlos Martínez y a otros profesionales influyentes, estaba claramente marcada por el modernismo de los CIAM.

La creación de una nueva oficina se justifica también por la aparición de nuevas necesidades, o al menos, de nuevas interpretaciones sobre las responsabilidades gubernamentales Es decir, si se consideró necesario modificar la estructura existente fue también porque se consideró que los organismos existentes no satisfacían las necesidades actuales de la ciudad. Con base en esta idea, el decreto planteó una lista de tareas y la expuso en el artículo 4. Esta lista condensa las labores que el gobierno les asignó a los expertos de urbanismo.

“Artículo $4^{\circ}$ La elaboración del plano regulador de la ciudad debe basarse de preferencia en los estudios detenidos que se hagan sobre los siguientes puntos:

a) Localización, topografía, geología y climatología de la ciudad;

\footnotetext{
${ }^{15}$ Ibídem.

${ }^{16}$ Ibídem.
}

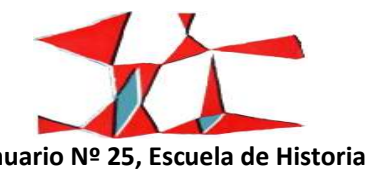


b) Estudio detenido de la historia de la ciudad respecto al crecimiento de la población, comercio, industria, sitios históricos, monumentos, necesidades del Gobierno, tránsito en las calles, habitación, etc.

c) Población total en las distintas épocas y en relación con la población de otras ciudades colombianas, suramericanas o de cualesquiera otros países, cuyo estudio pueda ser interesante para el desarrollo de Bogotá. Los proyectos y cálculos debe ser previstos para un periodo de desarrollo de la ciudad, siquiera de 50 años de hoy en adelante.

d) Distribución actual de la población de la ciudad y distribución probable durante el desarrollo de todo el período de cincuenta años mencionado atrás.

e) Necesidades presentes y futuras de la ciudad respecto al desarrollo del tránsito en sus calles, de los transportes por ferrocarril, por avión o por otros medios, tránsito interno, áreas comerciales, áreas industriales, parques públicos y edificios públicos.

f) Localización de las estaciones de ferrocarril, vías de acceso por carretera, aeródromos oficiales y privados, etcétera.

g) Uso, localización y relocalización de avenidas y calles; de las ampliaciones que haya que hacer a las existentes y de las nuevas que sea necesario abrir, todo relacionado con los índices estadísticos que rigen en los estudios sobre población, tránsito, etc.

h) Sitios de estacionamiento para automóviles, tanto en las calles públicas como en los lugares privados, y reglamentación de los mismos.

i) Circulación de buses y necesidades futuras al respecto, fijando ratas permanentes e indicando las nuevas que sea necesario abrir de acuerdo al crecimiento de la ciudad.

j) Tránsito aéreo, presente y futuro, y necesidad de los aeropuertos.

k) Tránsito inter-urbano, comercial y de pasajeros, su desarrollo probable y necesidades para el futuro.

124

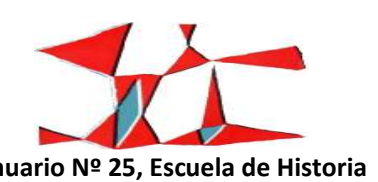

Revista Digital № 4, Facultad de Humanidades y Artes, Universidad Nacional de Rosario, 2013

ISSN 1853-8835 
I) Suministro de agua en el presente y en el futuro, en tal forma que se prevea la red de distribución de acuerdo con la expansión de la ciudad.

m) Alcantarillado y drenajes existentes y futuros que sea necesario proyectar de acuerdo con el desarrollo de la ciudad.

n) Recolección de las basuras y forma de incineración por los sistemas modernos.

o) Estudio de los parques y lugares de recreo, tanto oficiales como privados y respecto de la expansión adicional que sea necesario a este respecto para el futuro.

p) Edificios públicos y administrados por la Nación, el Departamento o la Ciudad, y disposiciones relativas a esa administración en lo que respecta a la ciudad, tanto en el área central como en los suburbios. Localización de los edificios para la policía, los bomberos y la sanidad.

q) Instituciones públicas y semipúblicas, tales como iglesias, hospitales, etc., escuelas públicas y privadas y facilidades para su construcción tanto en el presente como en el futuro.

r) Salones o centros de cultura en los barrios.

s) Estudio de las habitaciones para determinar todas las condiciones presentes y las necesidades y sistemas para el futuro.

t) Estudio del desarrollo industrial, tanto presente como futuro, y zonificación respectiva dentro del plano general.

u) Aspecto general de la ciudad para colocar los hidrantes, el alumbrado de las calles, los postes, los vertederos y la disposición de las calzadas.

v) Control de las edificaciones públicas y privadas y organización de la comisión que debe aprobarlas.

w) Revisión de la zonificación actual para determinar las modificaciones que deban hacérsele dentro de la técnica moderna del urbanismo.

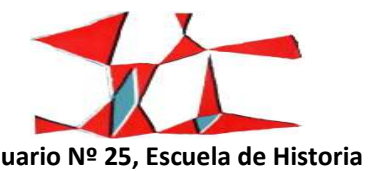


Revisión del Código Sanitario actual y elaboración de uno moderno que cubra todas las necesidades." ${ }^{17}$

Esta lista muestra un interés explícito de la alcaldía por establecer nuevas bases técnicas para la elaboración del plan regulador. De hecho, si miramos la lista con atención, el objetivo de la nueva oficina era, ante todo, comprender la ciudad con base en las categorías de análisis del modernismo. Nuevamente, es claro que las tareas a realizar fueron definidas con gran detalle lo cual demuestra que el gobierno buscaba controlar este nuevo proceso desde las consignas más básicas hasta los elementos prácticos. Los estudios hechos por la SOP y el Departamento de Urbanismo bajo la dirección de Brunner durante los años 1930 fueron ignorados por esta nueva configuración política y profesional. De esta manera, la OPRB se constituyó como un centro de estudios de urbanismo y no como un nuevo organismo ejecutivo.

La organización de la OPRB hecha por la Alcaldía determinó que el Plan regulador debía desarrollarse en cinco etapas. "Primera etapa, análisis de las condiciones actuales de la ciudad; Segunda etapa, esquema básico preliminar; Tercera etapa, plan director o anteproyecto; Cuarta Etapa, plan regulador o planos generales urbanísticos y Quinta Etapa, desarrollo del plan."18 El trabajo que los urbanistas extranjeros, Le Corbusier y TPA de José Luis Sert y Paul Lester Wiener debían realizar solamente consistía en las etapas 2, 3 y 4 . De tal manera que, con base en estudios anteriores realizados por la OPRB, los expertos extranjeros debían realizar esquemas y diseños técnicos, así como un plan piloto al cual debían darle seguimiento con el plan regulador. En ese sentido, el compromiso de los urbanistas extranjeros no supone una reestructuración institucional.

Los urbanistas extranjeros iniciaron en sus talleres el trabajo desde el momento en que firmaron sus contratos. Por su parte, la OPRB se mantenía en contacto permanente con los expertos y tomaba en cuenta las propuestas e ideas que éstos le transmitían. Sin embargo, la situación política local seguía siendo extremadamente complicada. Los esfuerzos de Ospina por restablecer el orden público, calmar las tensiones políticas y controlar la violencia eran insuficientes y era imposible poner en marcha proyectos en los distintos órganos ejecutivos. A pesar de la prontitud con la cual Le Corbusier entregaba sus diseños iniciales,

\footnotetext{
${ }^{17}$ Ibídem.

${ }^{18}$ Municipio de Bogotá; Contrato para la prestación de servicios como urbanista consultor en la elaboración del Plan Regulador para Bogotá con el arquitecto Le Corbusier; Fundación Le Corbusier (en adelante, FLC); Archivo digital; H3-4-473.001.
}

126

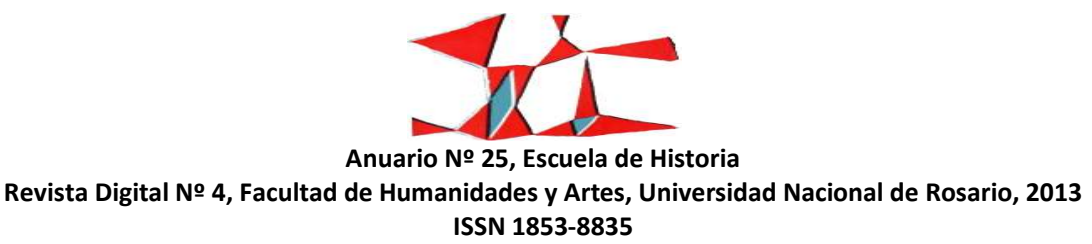


la respuesta del lado colombiano era lenta. Wiener, más al tanto de los acontecimientos que ocurrían en

Bogotá explicaba la complejidad de la situación política local de la siguiente manera.

“Debido al conflicto político en Colombia, no ha llegado [a Nueva York] la solicitud del seguro; todas las actividades en Colombia están estancadas; se espera en cualquier momento una guerra civil. Es imposible predecir cómo la situación política va a afectar el trabajo. Le he recomendado a Ritter permanecer completamente callado y no participar de manera directa o indirecta en política, sino que se mantenga en una posición neutra y técnica, para que el Plan de la Ciudad no se lleve a la batalla política donde sería utilizado inescrupulosamente como "fútbol" político." 19

Coordinar la acción institucional con los nuevos proyectos y cambios propuestos por Le Corbusier, Wiener y Sert, ciertamente no era fácil. No fue sino hasta abril de 1951, que la ciudad logró dar continuidad al proceso iniciado con la ley 88 de 1947. Mediante el decreto $185^{20}$, la alcaldía adoptó oficialmente los diseños, planes y la larga lista de transformaciones propuestas por los extranjeros. De esta manera, el ejecutivo local se comprometió con una serie de acciones que necesitaban de un funcionamiento institucional armónico. No obstante, la realidad política y social seguía siendo inestable y al igual que el gobierno de Ospina, la administración de Laureano Gómez, elegido en 1950, no lograba controlar la violencia política en el país.

En junio de 1953, por las dificultades mismas de la configuración socio-política nacional, la etapa de desarrollo del proyecto aún no había comenzado, el sistema institucional y político fue interrumpido por un golpe de Estado. El orden institucional cambió radicalmente y el gobierno de Laureano Gómez fue derrocado por los militares dirigidos por Gustavo Rojas Pinilla. Y, si bien se mantuvieron vigentes instituciones como la Secretaría de Obras Públicas o la OPRB, las jerarquías institucionales así como las estrategias de justificación y los garantes de legitimidad cambiaron completamente. Consideramos este acontecimiento como un punto de inflexión ya que marcó el fin de un desarrollo institucional comenzado en 1947 cuyo objetivo era

\footnotetext{
${ }^{19}$ Wiener, Paul Lester; "Carta a Le Corbusier"; Nueva York; 8 de noviembre 1949; FLC; H3-4-173-001. "Due to political strife in Colombia, the necessary insurance application has no yet arrived, all activities in Colombia are at standstill, civil war is expected momentarily. Just how the political situation in Colombia will affect work is impossible to predict. I have advised Ritter to remain completely quiet and not to participate directly or indirectly in politics but to stand on the completely neutral grounds of a technician, so as not to draw the City Plan into the political battle where it would only be used unscrupulously as political "football"."

${ }^{20}$ Municipio de Bogotá; “Decreto número 185 de 1951”; en Registro Municipal; Imprenta Municipal; Bogotá; 16 de mayo de 1951; Año LXXI; № 433 a 441; pp. 43-54.
}

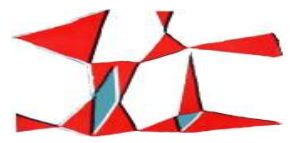

Anuario № 25, Escuela de Historia 
transformar la estructura que se encargaba del urbanismo de la capital.

Finalmente, podemos decir que entre 1947 y 1953 hubo una serie de cambios gubernamentales que generaron una nueva configuración institucional para desarrollar el urbanismo de Bogotá. La cual se caracterizó por tres elementos fundamentales. En primer lugar, a diferencia de lo ocurrido en los años 1930 y hasta mediados de la década de 1940, era el Estado Nacional el principal responsable de dirigir el urbanismo de la capital. Asimismo, el ejecutivo municipal abandonó sus funciones como cabeza del urbanismo de la capital y se limitó a ejecutar los mandatos del gobierno nacional. En segundo lugar, hubo un cambio de doctrina de urbanismo que abandonó los desarrollos hechos por Karl Brunner y su modernidad académica. Las autoridades nacionales y locales optaron por el urbanismo moderno de Le Corbusier y los CIAM y con base en esto establecieron nuevos esquemas directores para Bogotá. Y finalmente, el ambiente político inestable y violento de la ciudad y el país generaron un clima en el cual la realización de cualquier proyecto era una empresa incierta y casi imposible.

\section{Buenos Aires, el modernismo de la revolución}

En junio de 1943 un golpe de Estado derrocó al presidente Ramón Castillo en Argentina. El general Pedro Pablo Ramírez tomó temporalmente el control del gobierno federal y nombró en la intendencia de Buenos Aires al General Basilio Pertiné. El nuevo gobierno se presentaba como revolucionario y pretendía desmontar la estructura institucional vigente. Sin embargo, era un régimen de transición con fecha de vencimiento que en lo que respecta al urbanismo no estableció reformas revolucionarias y por el contrario mantuvo las estructuras institucionales creadas desde los años 1930. De hecho, una de las primeras acciones del Intendente Pertiné consistió en reforzar una Comisión de Legislación y Finanzas de la Dirección del Plan Regulador ${ }^{21}$ creada por el gobierno anterior.

Enseguida, en 1944, el General Edelmiro Farrel fue nombrado presidente de la nación y en el poder municipal se designó a César R. Caccia. A diferencia de sus antecesores, durante este gobierno se ordenó reestructurar la Dirección General de Obras Públicas y Urbanismo de Buenos Aires. Esta iniciativa fue lanzada mediante el decreto $10927 / 44^{22}$ por el poder ejecutivo nacional y retomada en el decreto municipal

${ }^{21}$ Municipalidad de la Ciudad de Buenos Aires; Boletín Municipal; Buenos Aires; martes 20 de julio de 1943; Año XX; № 6900, p. 1298.
${ }^{22}$ Municipalidad de la Ciudad de Buenos Aires; “Decreto 10927/44”; en Boletín Municipal; Buenos Aires; miércoles 31 de mayo de $1944 ;$ Año XXI; № 128

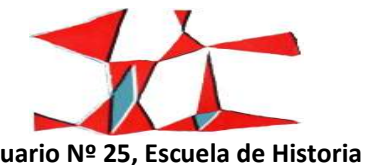


1647 del 15 de mayo del mismo año ${ }^{23}$. Si bien estos textos dan inicio a una reforma institucional, se puede decir que ésta fue apenas parcial. De hecho, Carlos Maria Della Paolera, quien en 1932 diseñó la estructura institucional sobre la cual se construyó el sistema porteño de urbanismo, mantuvo su puesto de subdirector de urbanismo. Igualmente, la transición definida por este decreto quedó incompleta puesto que sus funciones no se reglamentaron sino hasta el 11 de julio de 1945 mediante el decreto 2862/945 ${ }^{24}$.

Se puede ver entonces que, a pesar de que la revolución del 43 pretendió ser un cambio institucional radical, las primeras modificaciones institucionales se hicieron lentamente. Del mismo modo, los cambios en las estructuras que servían de base al urbanismo capitalino fueron leves y conservaron elementos fundamentales de los gobiernos anteriores. Se mantuvo, por ejemplo, a Carlos Maria Della Paolera en una cartera, que aunque había cambiado de nombre, era muy similar a la que existía anteriormente. Por lo tanto, más que una revolución, para los efectos del urbanismo porteño, lo que ocurrió entre 1943 y 1946 fue una gradual transición no democrática cuyos resultados no definieron nuevos roles para el urbanismo local.

En 1946 Juan Domingo Perón ganó las elecciones presidenciales y se instaló en la Casa Rosada. A pesar de pertenecer a la coalición que organizó la Revolución de 1943, Perón no se consideraba a sí mismo como el heredero de un líder anterior. Por el contrario, se reivindicaba como el líder de una nueva Argentina. Para los intereses del presidente el porvenir de la ciudad capital era fundamental, según Anahí Ballent "La idea de creación de una ciudad nueva, de transformación radical del medio urbano, no dejaba de seducir a un gobierno que en muchos aspectos se asignaba un carácter fundacional, que ansiaba erigirse como constructor de un nuevo país." ${ }^{25}$ La revolución del 43, así como el fin de la segunda guerra mundial eran acontecimientos reconocidos por la población en general que legitimaban este discurso político de cambio. De hecho, cuando Emilio Siri asumió el cargo de Intendente de Buenos Aires resaltó públicamente que la generación política a la cual tanto él como el presidente Perón pertenecían era el resultado de la Revolución

\footnotetext{
7150; pp. 1196-1201.

${ }^{23}$ Ibídem.

${ }^{24}$ Municipalidad de la Ciudad de Buenos Aires; "Reglamentación de funciones de la Dirección General Obras Públicas y Urbanismo"; en Boletín Municipal; Buenos Aires; sábado 9 de junio de 1945; Año XXII; № 7443; pp. 1406-1413.

${ }^{25}$ Ballent, Anahí; Las huellas de la política. Vivienda, ciudad, peronismo en Buenos Aires, 1943-1955; Universidad Nacional de Quilmes-Prometeo; Buenos Aires; 2005; p. 35.
}

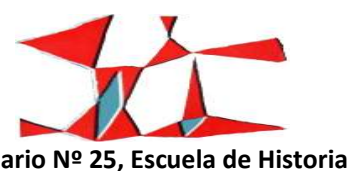


del 43 y del apoyo manifestado por el pueblo en las elecciones ${ }^{26}$. En ese sentido, los nuevos líderes políticos no se mostraban a sí mismos como herederos de Pedro Ramírez o Edelmiro Farrel y mucho menos de Justo, por el contrario, consideraban que sus posiciones de poder eran el resultado de su propia lucha desde 1943. Este discurso, ante todo, permitía establecer un gobierno de ruptura. Era en estos términos que el nuevo ejecutivo municipal buscaría, como veremos, aprobar reformas cuyo objetivo principal era reestructurar la administración nacional, y del mismo modo, la de la capital federal.

Como es usual en la política, las reformas comenzaron por la nomenclatura. Uno de los primeros actos consistió en fijar nuevos nombres para las delegaciones responsables del urbanismo de Buenos Aires. Cambiar la denominación oficial podría parecer un desplazamiento político secundario puesto que no implicaba ajustes presupuestales ni sugería, en apariencia, conflictos económicos. Sin embargo, sí era un gesto importante ya que permitía establecer nuevas bases lingüísticas entre la política y el urbanismo. De esta manera, se podían crear nuevas asociaciones entre política, técnica y lenguaje que a su vez, eran fundamentales para justificar transferencias de responsabilidades al interior de las divisiones administrativas del gobierno.

Los nombres oficiales desde la reforma de Farrel y Caccia en 1944 eran: Secretaría de Obras Públicas e Industrias, y Dirección General de Obras Públicas y Urbanismo, y los nuevos nombres establecidos por el Decreto 5600/947 eran Secretaría de Obras Públicas y Urbanismo y Dirección General de Obras y Planeamiento ${ }^{27}$. Este cambio correspondía con el interés del gobierno federal de realizar una reforma administrativa general de la capital. Pero, más que un proceso burocrático, se trataba de re-politizar el urbanismo que, gracias al trabajo de Carlos María Della Paolera durante los años 1930 se había convertido en una labor primordialmente técnica y relativamente independiente de la vida política nacional. De esta manera, el término "Urbanismo" se asoció directamente a una Secretaría Municipal dependiente del Intendente y no a una "Dirección General". Las "Direcciones Generales" eran organismos ejecutivos

\footnotetext{
${ }^{26}$ Siri, Emilio P.; "Palabras pronunciadas por el Doctor Emilio P. Siri al asumir las funciones de intendente municipal”; en Boletín Municipal; Buenos Aires; 8 sábado de junio de 1946; Año XXIII; № 7731; p. 1158. “No habiendo escatimado, desde el primer instante, mi adhesión política a la acción reparadora y constructiva iniciada el 4 de Junio de 1943, mal podía haberla restado en lo administrativo, ahora que comienza el ciclo de su estructuración definitiva, con el espaldarazo de la voluntad nacional manifestada en comicios ejemplares."

${ }^{27}$ Municipalidad de la Ciudad de Buenos Aires; “Decreto núm.5600/947”; en Boletín Municipal, Buenos Aires; jueves 31 de julio de 1947; Año XXIV; № 8060; p. 1668. Buenos Aires, julio 30 de 1947. "Artículo $1^{\circ}$. - La actual Secretaría de Obras Públicas e Industrias se denominará en adelante Secretaría de Obras Públicas y Urbanismo, Artículo $2^{\circ}$. - La actual Dirección General de Obras Públicas y Urbanismo se denominará en adelante Dirección General de Obras y Planeamiento.
}

130

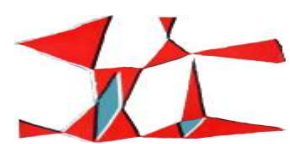

Anuario № 25, Escuela de Historia

Revista Digital № 4, Facultad de Humanidades y Artes, Universidad Nacional de Rosario, 2013 ISSN 1853-8835 
dependientes de una Secretaría Municipal que a su vez estaba subordinada a la Intendencia cuya legitimidad recaía sobre el gobierno federal. Esta condición las hacía poco visibles y al mismo tiempo, limitaba su capacidad de acción. Al elevar el término "urbanismo" al nivel de Secretaría este adquiría mayor visibilidad e importancia material, política y simbólica.

Igualmente, se empezó a utilizar, tanto en la administración municipal como en el gobierno federal, el término "Planeamiento". Según Ballent este cambio de terminología denota una nueva aproximación disciplinar a la ciudad en la cual la economía ocupa un lugar preponderante y donde además se hace referencia a la región y al territorio y no solamente a la ciudad ${ }^{28}$. El uso institucional de nuevos términos como éste era efectivamente una manera de legitimar la acción regional como parte del ejercicio de pensar la ciudad. Sin embargo la aparición del planeamiento no remplazó totalmente al urbanismo.

La permanencia del urbanismo era mucho más que una inercia lingüística. Si analizamos los perfiles de los principales protagonistas del sistema administrativo podemos ver cuáles eran las disciplinas sobre las que pretendía basarse el nuevo sistema de urbanismo de la municipalidad. Emilio Siri, el nuevo Intendente nombrado por Perón, nombró a un abogado, Guillermo Borda, como Secretario de Obras Públicas y Urbanismo; como cabeza de la dirección Autárquica de Obras Municipales fue nombrado Carlos Becker, arquitecto que había sido Secretario de Obras Públicas durante la administración de Caccia; como consejero técnico de la Secretaría de Obras Públicas se nombró al ingeniero Alejandro Aldázabal, antiguo director de la Dirección General de Obras Públicas y Urbanismo; y finalmente, como director de la nueva Dirección General de Obras y Planeamiento se designó al ingeniero Roberto Dupeyron, quien ya en 1944 trabajaba en la institución dirigida por Aldázabal ${ }^{29}$. Queda claro que la nueva estructura contaba con líderes cuyos perfiles no eran radicalmente distintos a los de los anteriores. Es más, varios de ellos habían trabajado con las administraciones precedentes. La ingeniería y la arquitectura seguían siendo las bases doctrinales tanto del "urbanismo" como del "planeamiento".

Además, en septiembre de 1947, Siri creó el Consejo Municipal de Obras Públicas cuya misión,

\footnotetext{
${ }^{28}$ Ballent, Anahí; Las huellas de la política; Ob. Cit.; p. 92. "El problema terminológico es aquí central, ya que señala un nuevo enfoque para la disciplina que, por un lado, no pretende restringirse sólo a la ciudad, sino que intenta abarcar el territorio, y, por otro, sugiere una nueva relación más estrecha y directa- con la política y con la economía."

${ }^{29}$ Municipalidad de la Ciudad de Buenos Aires; “Decretos de designación en la Secretaría de Obras Públicas y Urbanismo”; en Boletín Municipal; Buenos Aires; sábado 2 de agosto de 1947; Año XXIV; № 8062; pp. 1691-1692.
}

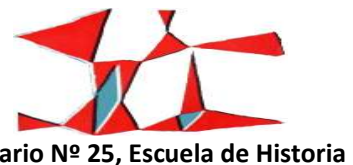


estaba definida de esta manera en el artículo №1 del Decreto 7368/947,

“Créase el Consejo Municipal de Obras Públicas, dependiente de la Secretaría de Obras Públicas y Urbanismo, con la misión de asesorar al Departamento Ejecutivo, previa realización de los estudios que estime pertinentes, respecto a la oportunidad, conveniencia y posibilidades financieras que presenten, en cada caso, las obras públicas o municipales ya gestionadas o que en lo futuro gestionen las Secretarías de la Intendencia, para el mejor cumplimiento de sus funciones." ${ }^{30}$

Los miembros de este consejo eran: como presidente, Aldázabal; como vicepresidente Dupeyron; y entre otros miembros vale la pena resaltar la presencia del subdirector de urbanismo, Carlos María Della Paolera. A diferencia de los otros miembros, Della Paolera fue relevado de sus funciones ejecutivas para dedicarse exclusivamente a este órgano consultivo. En cierta medida, se puede pensar que la creación de esta junta fue una estrategia de la municipalidad para deshacerse de la herencia del sistema establecido por Della Paolera desde 1932. Más allá de resaltar, tanto en las principales carteras dedicadas al urbanismo y planeamiento de Buenos Aires como en este consejo, la repetición de ciertos nombres conocidos, cabe anotar que estas actividades seguían estando en manos de arquitectos, urbanistas e ingenieros. La excepción era Borda, quien como vimos era abogado, pero no hay que olvidar que este nuevo Secretario era amigo personal del arquitecto y urbanista Jorge Ferrari Hardoy quien sería, más adelante, protagonista del urbanismo oficial de Buenos Aires. Así, se puede confirmar que la administración municipal no remplazó a sus cabezas ejecutivas por economistas. Sin embargo, entre los profesionales que siguieron en el nuevo organigrama municipal no todos compartían las mismas ideas y principios sobre cómo entender y dirigir y diseñar el presente y futuro de la ciudad.

En el mes de diciembre del mismo año, la Intendencia lanzó una iniciativa que abrió un nuevo espacio institucional para un urbanismo distinto al que había regido en la ciudad desde 1932. Mediante el decreto № 10898 se creó el Estudio para el Plan de Buenos Aires ${ }^{31}$. Para justificar este decreto el ejecutivo municipal consideró “...que se ha engendrado de manera pronunciada y sin responder a un plan u orden

\footnotetext{
${ }^{30}$ Municipalidad de la Ciudad de Buenos Aires; "Créase el Consejo Municipal de Obras Públicas”; en Boletín Municipal; Buenos Aires; viernes 26 de septiembre de 1947; Año XXIV; № 8106; p. 2094. “(Expte. 133.589 -1947). Decreto № 7368/947; septiembre 24 de 1947."

${ }^{31}$ Municipalidad de la Ciudad de Buenos Aires; “Creación del 'Estudio del Plan De Buenos Aires'”; en Boletín Municipal; Buenos Aires; sábado 27 de diciembre de 1947; Año XXIV; № 8178; pp. 2826-2828. "Decreto N. ${ }^{10898 / 947 " ~}$
}

132

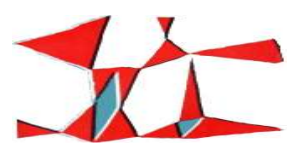

Anuario № 25, Escuela de Historia

Revista Digital № 4, Facultad de Humanidades y Artes, Universidad Nacional de Rosario, 2013 ISSN 1853-8835 
preconcebido, una urbe de tamaño y población desmesurados en relación con el resto del país..." ${ }^{32}$. Igualmente consideraba que la planeación de la ciudad capital y del país era impostergable. En ese sentido, decretó "Que para llevar a cabo los fines enunciados es necesario la creación de un organismo que estudie y proyecte en sus diversos aspectos: urbanístico, arquitectónico, jurídico y financiero, un plan que dirija el crecimiento y evolución de la Ciudad de Buenos Aires." ${ }^{33}$ Con base en este decreto se concretizó de manera oficial el interés del gobierno federal de hacer de la ciudad capital uno de los estandartes principales del nuevo gobierno. De esta manera, gracias al contacto privilegiado que Borda tenía con Ferrari Hardoy el urbanismo moderno de Le Corbusier y los CIAM encontró por primera vez en Buenos Aires un espacio institucional de acción. Según Ballent,

"Lo que estos arquitectos no habían logrado insertar en las administraciones de los años 1930 cobraba vida en la gestión peronista, gracias a una combinación de factores de distinto tipo: la importancia que el gobierno asignaba a la planificación, al entusiasmo que despertaba la arquitectura moderna en algunos sectores de la nueva gestión y la amistad entre Borda y Ferrari." ${ }^{34}$

Si bien los dos primeros factores señalados por Ballent hacen parte de la configuración que explica la llegada del modernismo de los CIAM a los espacios oficiales, el elemento fundamental es la amistad entre Borda y Ferrari Hardoy. Pues, por una parte es claro que las administraciones anteriores también asignaban una gran importancia al urbanismo. Prueba de esto es la presencia permanente de urbanistas en el gobierno municipal desde la aprobación del Plan Noel en 1925, pasando por el plan de urbanización de Carlos María Della Paolera, hasta la reforma de Caccia en 1944. Por otra parte, el entusiasmo que la arquitectura moderna generaba en la Argentina existía desde hacía muchos años. De hecho, la visita de Le Corbusier a Buenos Aires tuvo lugar en 1929 y desde entonces había canales profesionales mediante los cuales esta doctrina se mantenía vigente. Sin embargo, no fue sino hasta 1947 que, gracias a Borda y Ferrari Hardoy, se tejió un vínculo real entre el gobierno local y este grupo de profesionales del urbanismo.

El trabajo propuesto al EPBA no buscaba reestructurar el sistema institucional de urbanismo y planeamiento de la ciudad, ni tampoco se creó un espacio institucional nuevo para incorporar a este nuevo

\footnotetext{
${ }^{32}$ Ibídem.

${ }^{33}$ Ibídem. Eliminado de la cita: "...y que paralelamente a dicha labor proyecte aquellas obras de carácter urbanístico que se consideren necesarias para demostrar la nueva estructuración de la Ciudad..."

${ }^{34}$ Ballent, Anahí; Las huellas de la política; Ob. Cit.; p. 221.
}

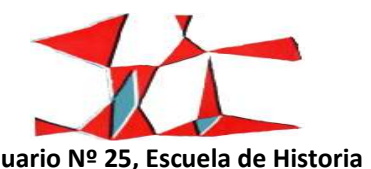


grupo de urbanistas. El nuevo organismo, como lo define el artículo 5 del decreto 10898 establece que "El actual Departamento de Urbanismo de la Dirección General de Obras y Planeamiento pasará a depender del Estudio del Plan de Buenos Aires, con todo su personal, asignaciones, materiales y expedientes en trámite previo inventario del mismo, debiendo reestructurarse sus funciones dentro de las finalidades del presente Estudio." ${ }^{35}$ De esta manera, el nuevo urbanismo porteño se instalaba sobre la oficina que un mes atrás era dirigida por Della Paolera. El mensaje era claro y con esto se pretendía disminuir la enorme influencia que el urbanista argentino aún tenía en las entrañas institucionales del urbanismo local.

La Intendencia buscaba reanimar las ideas desarrolladas por Ferrari Hardoy y Juan Kurchan bajo la dirección de Le Corbusier en 1938. Al mismo tiempo, se buscaba eliminar la herencia doctrinal de Della Paolera, pero sin deshacer sus desarrollos institucionales. Es decir, se mantenía la estructura institucional construida desde 1932 con modificaciones pero los contenidos de urbanismo eran remplazados por otros. Con base en esto, se retomaba un antiguo proyecto de urbanismo, de 1937-38 pero con algunos recursos nuevos.

A pesar de acercarse a un proyecto del cual uno de sus autores principales era Le Corbusier, Borda no tenía ningún interés por vincular al francés con un contrato con la municipalidad. Además es importante señalar que Borda había sido miembro del grupo FORJA $^{36}$ y, por lo tanto, no apoyaba la inclusión de extranjeros en el equipo encargado de definir los designios de la capital federal. Sin embargo, el vínculo entre Le Corbusier y el proyecto del EPBA era estrecho y la exclusión del urbanista francés llegó a ser motivo de conflicto con sus discípulos argentinos. Pues, el europeo consideraba que los argentinos se habían aprovechado de él y se habían apropiado injustamente de su trabajo. Pero Borda no era el único que rechazaba la inclusión de Le Corbusier, tampoco Siri ni Perón respondieron a los llamados del francés. Los reclamos del urbanista franco-suizo terminaron de manera abrupta y conflictiva, pero el urbanismo, al menos desde el punto de vista institucional, se hacía cada vez más argentino y menos europeo.

La existencia del EPBA como subdivisión oficial de la Intendencia estaba limitada a tres años por el artículo № 1 del decreto 10898. Esta limitación temporal muestra el estilo administrativo del gobierno

\footnotetext{
${ }^{35}$ Municipalidad de la Ciudad de Buenos Aires; “Creación del 'Estudio Del Plan De Buenos Aires””; Ob. Cit.; pp. $2826-2828$.

${ }^{36}$ El grupo Fuerza de Orientación Radical de la Jóven Argentina, FORJA, se fundó en 1935 y buscó reivindicar las ideas de Hipólito Yrigoyen y defender la soberanía nacional. Ver: Jauretche, Arturo; FORJA y la década infame; Peña Lillo Editor; Buenos Aires; 1984.
}

134

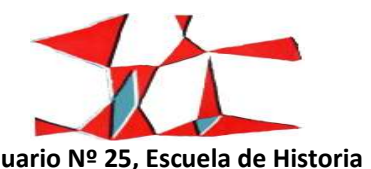


municipal, que aún sin tener resultados confiaba en su capacidad de transformar en poco tiempo la capital federal. Veamos pues las labores que la Intendencia de Buenos Aires fijó para el EPBA en el artículo 3 del decreto 10898,

“Art. $3^{\circ}$. -Serán funciones y atribuciones del Estudio del Plan de Buenos Aires:

1.) La preparación del expediente Urbano de la Ciudad de Buenos Aires; Los estudios del Plan de Buenos Aires; Los proyectos de legislación tendientes a la ejecución del Plan y su respectiva reglamentación, incluyendo la modificación del Código de la Edificación,

2.) Crear y organizar lo diversos departamentos técnicos y administrativos del Estudio;

3.) Proponer la contratación de los técnicos especialistas, nacionales o extranjeros, necesarios para el bueno desarrollo de los estudios y trabajos del Plan, los que tendrían categoría de Asesores del Consejo;

4.) Proyectar aquellas obras de carácter edilicio o urbanístico que se consideren necesarias para crear una conciencia urbanística, o para dar solución inmediata a problemas que así lo requieran;

5.) Disponer la realización de una campaña de divulgación popular de las finalidades del Plan, y sobre el estado de los estudios y conclusiones, mediante la utilización de la radio, cine, publicaciones, exposiciones, etc.:

6.) Asesorar sobre la ubicación y normas generales referentes a todas las obras públicas que encaren las diversas dependencias municipales;

7.) Proyectar los acuerdos con el Gobierno de la Provincia de Buenos aires, y las Municipalidades que se considere conveniente incluir en los estudios, tendientes a la confección del Plan del Gran Buenos Aires;

Elevar anualmente a la Superioridad, por intermedio del Consejero Ejecutivo, un informe del trabajo realizado." ${ }^{37}$

\footnotetext{
${ }^{37}$ Municipalidad de la Ciudad de Buenos Aires; “Creación del 'Estudio Del Plan De Buenos Aires”'; Ob. Cit.; pp. 2826-2828.
}

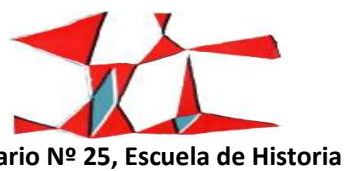


Los ocho puntos que definen las funciones y atribuciones del EPBA abrían un campo de acción amplio y diverso que se puede resumir en cuatro puntos. Por una parte, se le hace una serie de exigencias técnicas como la preparación de expedientes urbanos, estudios del plan, obras públicas y otras obras, reglamentos, planes de integración regional y redacción de informes de trabajo. En segundo lugar, se le exigía una labor legislativa de diseño de proyectos de leyes y de acuerdos. En tercer lugar, se le asignó una labor administrativa que demandaba la creación de puestos técnicos en la Intendencia y la contratación de personal. Y finalmente, debían difundir su trabajo en los diferentes medios de comunicación.

Estos cuatro elementos constituían una labor titánica que en el papel permitía transformar efectivamente la capital argentina. Sin embargo, demandaba también una capacidad de ejecución amplia que ciertamente superaba la capacidad real de este nuevo grupo, que hay que recordar, tan sólo ocupaba una sub-dirección general. De esta manera, se establecían labores difíciles y demandantes con plazos cortos y recursos económicos y administrativos limitados.

Un último elemento que es necesario señalar, eran las dificultades internas en la operación del EPBA. El grupo compuesto por Ferrari Hardoy, Bonnet, Roca, Vivanco y más tarde Kurchan, fue incapaz de superar obstáculos establecidos por sus mismos miembros. Según Liernur,

"Si bien Borda creó un cuerpo colegiado con el fin de despersonalizar la dirección de la oficina, la tarea ejecutiva sería desplegada, en la práctica, exclusivamente por Ferrari Hardoy y Bonet (y muy especialmente por este último en lo que a proyectos concretos se refiere, a pesar de largas ausencias del país) en forma discrecional. Miguel Roca, único consejero no adherente al grupo CIAM, era excluido sistemáticamente de las decisiones." ${ }^{38}$

De esta manera, es claro que la configuración institucional creada para el diseño y realización del EPBA traía consigo obstáculos que no estaba en capacidad de superar. Para empezar, se le asignaba un plazo corto para desarrollar una serie de labores amplias, diversas, y sobre todo complejas a nivel administrativo. Del mismo modo, la estructura institucional dentro de la cual se montó esta nueva oficina estaba relegada a una sub-dirección general cuya capacidad de acción y recursos eran limitados. Y finalmente, se había

\footnotetext{
${ }^{38}$ Liernur, Jorge Francisco y Pschepiurca, Pablo; La red austral. Obras y proyectos de Le Corbusier y sus discípulos en Argentina; Universidad Nacional de Quilmes-Prometeo; Buenos Aires; 2008; p. 344.
}

136

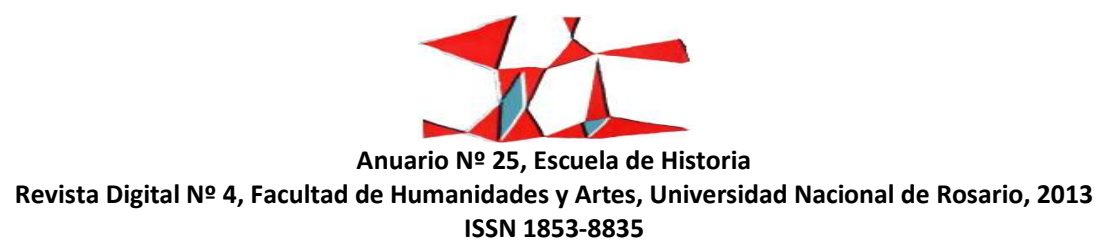


asignado estas labores a un grupo sin experiencia administrativa y que más que un interés de trabajo colectivo aportaba egos individuales y un desorden ejecutivo que le impedían funcionar de manera armónica y eficaz.

\section{Palabras finales}

Bogotá y Buenos Aires son ciudades capitales de dos países en los cuales las configuraciones sociopolíticas eran y son profundamente distintas. Sin embargo, a mediados del siglo XX dos acontecimientos políticos radicalmente diferentes generaron ciertas convergencias en la manera de pensar la ciudad. Por una parte, en Colombia, el partido Conservador retomó las riendas del gobierno nacional y buscó tomar el control directo del desarrollo urbano de la capital. Además, un clima de polarización política desató una crisis nacional violenta con consecuencias graves en la ciudad capital. Paralelamente, en Argentina, un movimiento político ubicado en el extremo opuesto del espectro político accedió al poder y de la misma manera intentó controlar el devenir de su capital. En ambos casos, las ideas en las cuales se basó el nuevo urbanismo provenían del modernismo de los CIAM. Estos cambios se basaron en los ideales políticos de los grupos que recientemente habían accedido al poder y al mismo tiempo demandaron transformaciones institucionales. Si bien la llegada de un nuevo urbanismo a la oficialidad municipal y nacional implica una larga lista de interrogantes de distinta naturaleza, en este artículo se buscó analizar tan sólo la relación entre el nuevo urbanismo y la transformación institucional.

Aunque los sistemas gubernamentales colombiano y argentino tenían grandes diferencias, con respecto a las instituciones que manejaban el urbanismo, antes de los cambios de mediados de los años 1940, había ciertas convergencias. En ambos casos se había desarrollado un sistema gubernamental municipal de urbanismo desde los años 1920. Éstos, durante los años 1930 habían constituido estructuras ejecutivas para realizar obras públicas, para controlar las obras particulares, y para dirigir el urbanismo general de la capital. En este tiempo se dotó a las instituciones municipales, de ambas capitales, de elementos técnicos nuevos, pero sobre todo de una estructura institucional con recursos y una relativa autonomía.

Las transformaciones políticas nacionales de la década de los años 1940 generaron necesidades para los nuevos grupos en el poder nacional que eran, en ambos casos, incompatibles con las estructuras

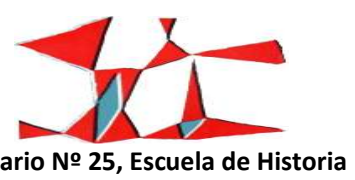


institucionales de las capitales. Sin embargo, desmontar estas estructuras era una difícil tarea que requería de nuevas justificaciones y garantes de legitimidad sólidos y basados en argumentos técnicos o científicos. Además, aunque las labores y necesidades políticas cambiaron, los protagonistas de las nuevas oficinas de urbanismo siguieron siendo profesionales de la arquitectura, la ingeniería y el urbanismo. En ambos casos había un número de grupos e individuos de diversas tendencias disciplinares que cumplían con las condiciones mínimas para renovar los contenidos del urbanismo municipal. Pero gracias a las estrategias y conexiones políticas de algunos individuos fue la doctrina modernista de los CIAM que, en ambos casos, logró abrir espacios en los nuevos esquemas gubernamentales.

A pesar de las convergencias que hubo en ambos procesos, hubo también importantes diferencias que marcaron divergencias fundamentales. En el caso bogotano no se puede olvidar que la vida política ocurría en medio de una violencia que sobrepasaba la capacidad de acción del gobierno en todas sus instancias. Por una parte, esta situación que era casi una guerra civil fue utilizada por los impulsores del nuevo urbanismo, como el mismo presidente Ospina, como argumento para legitimar la transformación institucional. Por otra parte, los autores principales de los proyectos de urbanismo prefirieron mantenerse al margen de las dificultades políticas y limitarse al aspecto técnico de su labor. Los expertos internacionales, a pesar de ser ellos quienes tenían la experiencia en el desarrollo de proyectos de urbanismo, fueron incapaces de definir de primera mano cómo debían ser las estructuras institucionales en las cuales pretendían operar. Por el contrario, a causa de su interpretación de la situación política, adaptaron su trabajo a las formas institucionales impuestas por las autoridades locales y nacionales.

En el caso argentino un golpe de estado dio lugar a la Revolución del 43 y a una primera camada de líderes políticos. No obstante, en un primer momento estos líderes no buscaron transformar la compleja estructura institucional en la cual se asentaba el urbanismo de la capital. Estos cambios, en un principio fueron lentos y graduales. Sin embargo, luego de la elección de Perón, que a diferencia de Ramírez y Farrel tenía una base popular amplia, el gobierno buscó acelerar la transformación institucional de los organismos que controlaban el urbanismo de la capital. A pesar de la solidez gubernamental, hubo serias dificultades para poner en marcha las propuestas. Estos problemas tenían sus orígenes en diferentes causas, por una parte, no hubo una transferencia de poder ni del ejecutivo municipal ni del gobierno federal, hacia los nuevos encargados del urbanismo de la capital. Y, por otra parte, la limitada capacidad de acción de esta 138

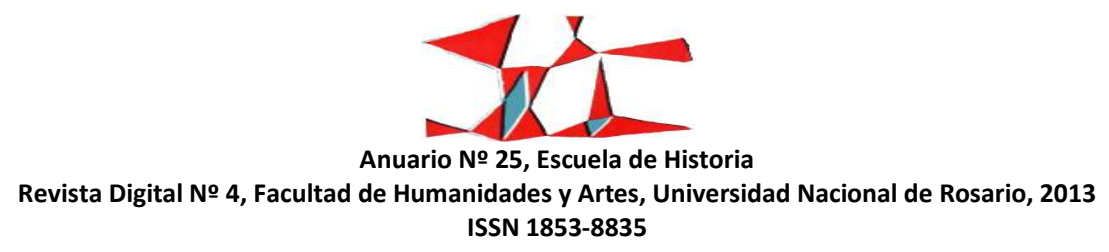


oficina obstaculizó su propio trabajo a causa de la incapacidad de sus miembros para trabajar de manera conjunta y eficiente.

Los procesos vividos por estas dos capitales son muestras de una realidad que afectó a todo el continente. El urbanismo moderno de los CIAM circuló de distintas maneras por los distintos países de América Latina dejando huellas y resultados diversos. Del mismo modo, grupos políticos distintos hicieron lecturas de este urbanismo con base en sus intereses particulares. Sin embargo, además de analizar las interpretaciones que los diferentes grupos hicieron del urbanismo y los intereses que motivaron su acción, queda claro que para entender el funcionamiento del urbanismo en un sistema gubernamental es necesario comprender la estructura institucional sobre la cual se establecen los proyectos. Entender cómo funcionan las instituciones gubernamentales permite comprender el rol y la importancia que se asigna a los proyectos impulsados por el gobierno.

Finalmente, luego de la exposición hecha en este artículo quedan interrogantes abiertos para entender las relaciones entre la política y el urbanismo. ¿Las doctrinas del urbanismo tienen un color político? O ¿fueron los proyectos de urbanismo moderno herramientas de manipulación política? Igualmente, sería necesario ampliar la comparación a otras ciudades para así generar un panorama amplio de la evolución institucional y del urbanismo en América Latina.

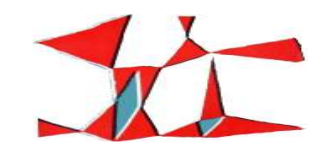

Anuario № 25, Escuela de Historia

Revista Digital № 4, Facultad de Humanidades y Artes, Universidad Nacional de Rosario, 2013

ISSN 1853-8835 

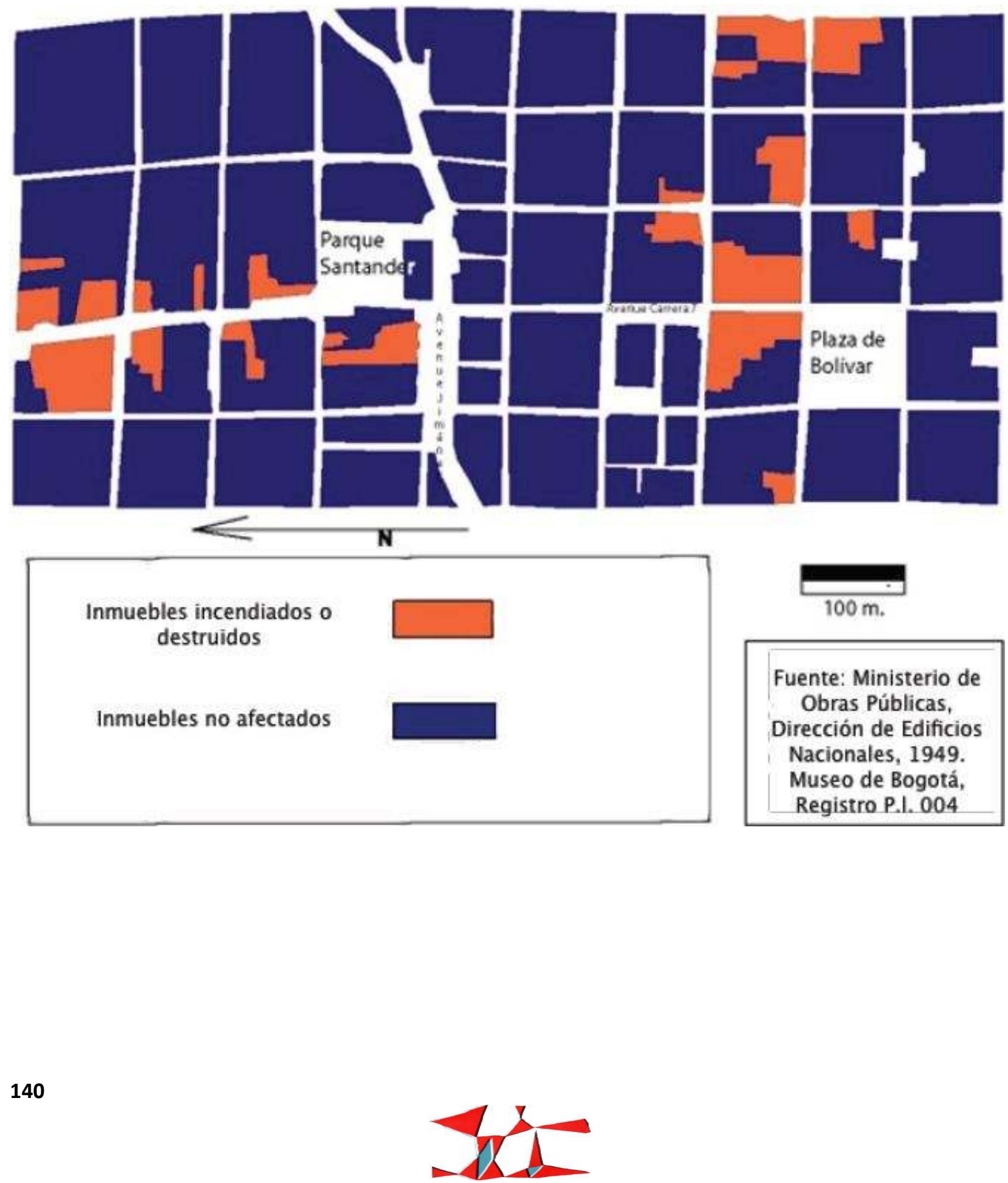


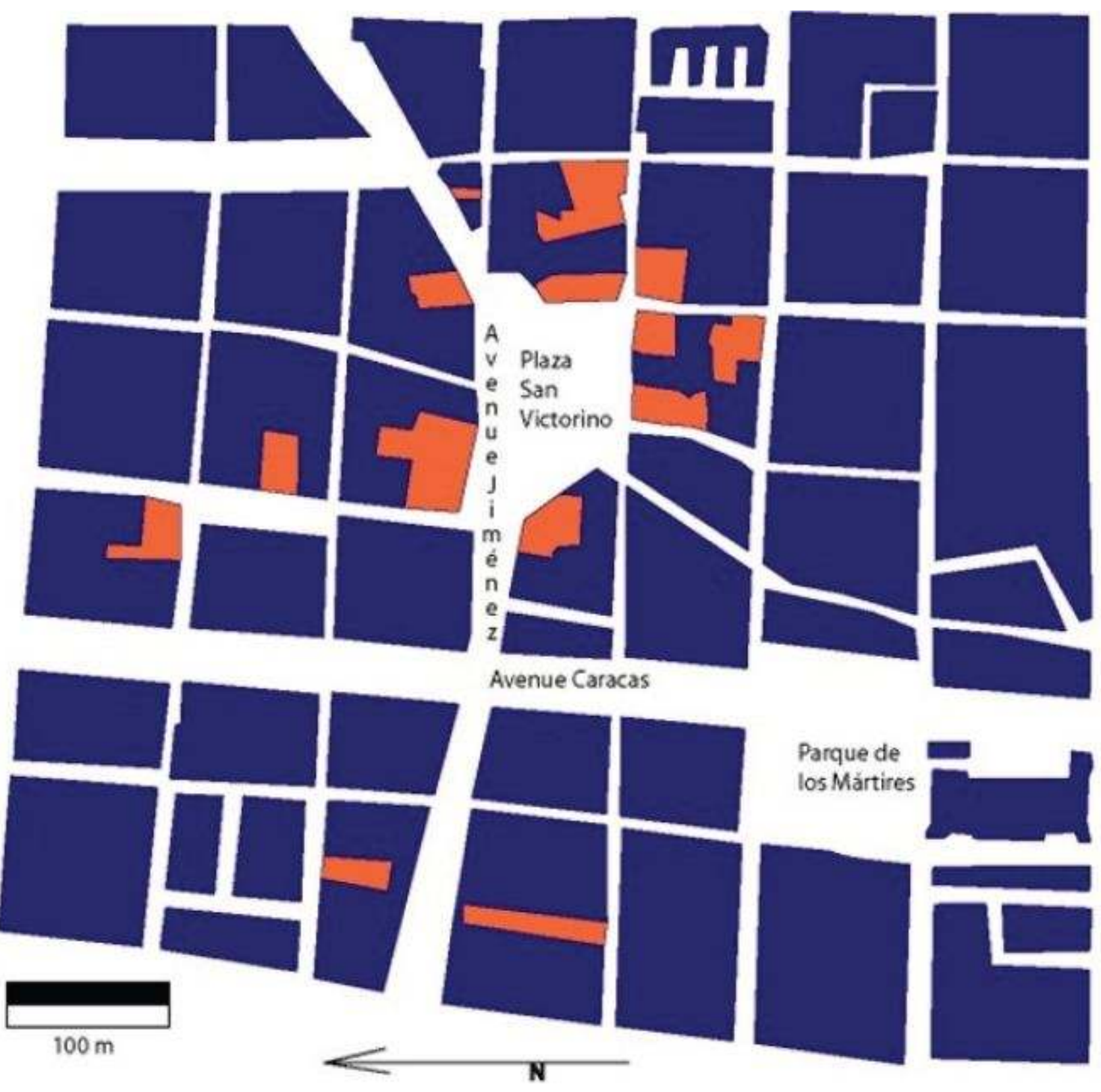

Recibido: 6 de mayo de 2013

Aprobado: 11 de julio de 2013

Versión final: 29 de septiembre de 2013

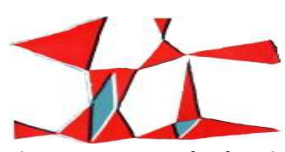

